\title{
Infraestrutura energética brasileira: perspectivas e desafios para 0 suporte aos veículos elétricos
}

O setor de transportes é considerado, mundialmente, como um dos que mais emitem gases de efeito estufa (GEE). Os veículos elétricos (EVs), por não emitirem GEE durante a operação, vêm sendo fortemente incentivados por governos, no Brasil e no exterior. Existe pouca discussão quanto à infraestrutura necessária para suportar a entrada deste segmento de veículos no mercado. A partir do cálculo do consumo de um modelo utilitário de EV, com base no perfil de uso brasileiro, este estudo mostra uma avaliação da infraestrutura energética necessária para suportar uma frota de EVs projetada até 2030 , frente ao potencial de geração de energia elétrica no Brasil, a partir de uma análise crítica e de viabilidade técnico-econômica dos dados obtidos. Os resultados mostraram a existência de uma importante defasagem de infraestrutura, destacando que os EVs podem não ser a melhor solução de mobilidade para o Brasil neste momento, sobretudo quando comparados com outras tecnologias, como os veículos movidos a biocombustíveis.

Palavras-chave: Veículos Elétricos; Infraestrutura Elétrica; Incentivos Governamentais; Biocombustíveis.

\section{Brazilian energy infrastructure: perspectives and challenges for supporting electric vehicles}

\begin{abstract}
The transport sector is considered, worldwide, as one of the most emit greenhouse gases (GHG). Due to this, electric vehicles (EV) for not emitting GHG during the operation, have been strongly encouraged through governmental incentives, in Brazil and abroad. Against these incentives, little is discussed about the infrastructure needed to support the entry of this vehicle segment into the market. Regarding the calculation of the consumption of an EV utility model, based on the Brazilian usage profile, this study aims to analyze the energy infrastructure necessary to support an EV fleet projected until 2030, in view of the potential for electricity generation in Brazil, from a critical analysis and technical-economic feasibility of the data obtained. The results showed the existence of an important infrastructure gap, highlighting that EVs may not be the best mobility solution for Brazil at this moment, especially when compared to other technologies, such as vehicles powered by biofuels.
\end{abstract}

Keywords: Electric Vehicles; Electrical Infrastructure; Government Incentives; Biofuels.

Topic: Sustentabilidade nos Transportes

Reviewed anonymously in the process of blind peer.

João Pinto Cabral Neto (iD

Instituto Federal de Alagoas, Brasil

http://lattes.cnpq.br/6343416990001721

http://orcid.org/0000-0003-4884-3392

cabralneto7@hotmail.com

Rejane Magalhães de Mendonça Pimentel (iD)

Universidade Federal Rural de Pernambuco, Brasil

http://lattes.cnpq.br/6974715752532263

http://orcid.org/0000-0003-3211-7601

rejanemmpimentel@gmail.com

Simone Machado Santos

Universidade Federal de Pernambuco, Brasil

http://lattes.cnpq.br/0184432775131107

http://orcid.org/0000-0003-1086-9140

smachados@hotmail.com
Received: 03/01/2021

Approved: 28/01/2021

\section{Referencing this:}

CABRAL NETO, J. P.; SANTOS, S. M.; PIMENTEL, R. M. M..

Infraestrutura energética brasileira: perspectivas e desafios para o suporte aos veículos elétricos. Revista Ibero Americana de Ciências Ambientais, v.12, n.1, p.385-396, 2021. DOI:

http://doi.org/10.6008/CBPC2179-6858.2021.001.0032 


\section{INTRODUÇÃO}

O setor de transportes é responsável por cerca de 14\% das emissões de gases de efeito estufa (GEE) no planeta. Em 2007, 63\% do total dessas emissões foi atribuído aos carros de passeio (PERUJO et al., 2011). Segundo dados do Sistemas de Estimativas de Emissões de Gases de Efeito Estufa (SEEG), o Brasil emitiu cerca de 2 bilhões de toneladas de $\mathrm{CO}_{2}$, apenas em 2017. Cerca de 21\% dessas emissões foram atribuídas ao setor de transporte e energia (WRI BRASIL, 2018).

Diante desta problemática global, os veículos elétricos (EVs) vêm se apresentando como uma alternativa no que se refere a mitigação dos GEE. Neste cenário, a China foi responsável por metade de todas as vendas de EVs no mundo. A Noruega representou o maior mercado consumidor de EVs, onde 39\% dos novos carros vendidos são elétricos (BNEF, 2018). Nesta perspectiva de expansão, especialistas indicam que $33 \%$ da frota global e 55\% dos veículos zero quilômetro comercializados, até 2040, serão elétricos (BNEF, 2018). A estratégia das políticas públicas de fomento considera que, através das boas práticas de regulação, os governos induzam a eficiência no mercado automotivo, onde montadoras produzam e consumidores adquiram cada vez mais EVs (FGV, 2018).

Segundo dados da Associação Nacional dos Fabricantes de Veículos Automotores (ANFAVEA), quanto à quantidade de carros licenciados, por tipo de combustível, no Brasil, é possível observar a evolução do mercado de automóveis do País (Tabela 1). O segmento de EVs, mesmo dentro do cenário de crise econômica, foi o único a apresentar taxa de crescimento positiva: crescimento de $178 \%$, quando comparado ao crescimento obtido entre os anos de 2019 e 2018; e de 299\%, somente para o ano de 2019 (ANFAVEA, 2019). Tais índices são reflexos das políticas públicas que visaram incentivar a eletrificação veicular.

Tabela 1: Dados do licenciamento total de automóveis, por combustível, no Brasil.

\begin{tabular}{lllllll}
\hline \multirow{2}{*}{ Combustível } & \multicolumn{1}{c}{ Licenciamentos } & \multicolumn{4}{c}{ Crescimento } & Taxa de Crescimento \\
& $\mathbf{2 0 1 7}$ & $\mathbf{2 0 1 8}$ & $\mathbf{2 0 1 9}$ & $\mathbf{2 0 1 9 / 2 0 1 8}$ & $\mathbf{2 0 1 8 / 2 0 1 7}$ & \\
\hline Gasolina & 68.902 & 81.935 & 73.853 & $90 \%$ & $119 \%$ & $-29 \%$ \\
Elétrico & 3.296 & 3.970 & 11.858 & $299 \%$ & $120 \%$ & $178 \%$ \\
Flex Fuel & 1.927 .221 & 2.168 .173 & 2.328 .650 & $107 \%$ & $113 \%$ & $-5 \%$ \\
Diesel & 176.565 & 221.260 & 251.222 & $114 \%$ & $125 \%$ & $-12 \%$ \\
\hline
\end{tabular}

Fonte: Adaptado de ANFAVEA (2019).

A maioria dos modelos de EVs existentes no Brasil são importados e possuem isenção do imposto de importação. No entanto, visando mudar este cenário e fomentar a produção destes veículos nacionalmente, e tomando por parâmetro metas de redução de emissão de $\mathrm{CO}_{2} / \mathrm{km}$ rodado, como praticado em outros países, podem-se destacar duas políticas governamentais como marcos da eletrificação veicular no Brasil, o Programa de Incentivo à Inovação Tecnológica e Adensamento da Cadeia Produtiva de Veículos Automotores (Inovar-Auto) e o Programa de Mobilidade - Rota 2030 (Figura 1).

O Inovar Auto, criado pela Lei $n^{\circ} 12.715$ (BRASIL, 2012), configurou-se como uma iniciativa do Governo brasileiro para fomentar ganhos sistêmicos de eficiência e aumento de produtividade da cadeia automotiva. Os incentivos tributários do programa foram direcionados a novos investimentos, à elevação do padrão tecnológico dos veículos e de suas peças e componentes, e à segurança e eficiência energética veicular. Apesar do Inovar Auto não se referir, necessariamente, à eletrificação veicular, ele foi o primeiro 
grande programa a tratar da eficiência energética dos veículos, criando um ambiente favorável para que o Governo brasileiro pudesse promulgar metas ainda mais arrojadas, no futuro.

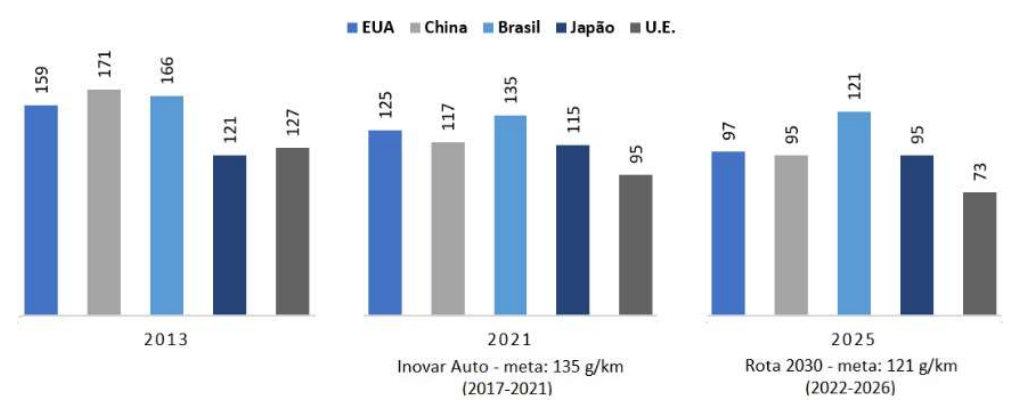

Figura 1: Metas mundiais (Estados Unidos, China, Japão, União Europeia e Brasil) de emissões veiculares, em gramas de $\mathrm{CO}_{2}$ por km rodado, nos anos de 2013, 2021 e 2025. Fonte: Adaptado de Moura (2019).

O Rota 2030, criado pela Lei $\mathrm{n}^{\circ} 13.755$ (BRASIL, 2018), surge como programa governamental em substituição ao Inovar Auto, visando tornar mais rígidas as metas de emissão de GEE. Com este subsídio, a alíquota de imposto sobre produtos industrializados (IPI) sobre os EVs que inicialmente era de 25\%, passará a ser de $7 \%$ até $18 \%$, variando de acordo com a eficiência energética do motor. Quanto maior a eficiência energética, menor a alíquota incidente sobre o EV. Os fabricantes de veículos convencionais (motor a combustão) que baterem a meta de eficiência sem, no entanto, migrarem para a eletrificação veicular, ganharão desconto de apenas um ponto percentual sobre o IPI que é de 25\% (BRASIL, 2018). Ainda, de acordo com o programa Rota 2030, além da renúncia tributária anual, estimada em $\mathrm{R} \$ 1,5$ bilhão pelo Governo, as empresas do segmento automotivo que aderirem e fizerem investimentos em inovação poderão gerar créditos de até $30 \%$ do valor dos veículos para abater sobre o imposto de renda (IR) ou sobre a contribuição social sobre o lucro líquido (CSLL). Quando os investimentos forem realizados em áreas consideradas estratégicas pelo Governo, como no desenvolvimento de baterias para EVs, o abatimento poderá chegar à 40\%. Da mesma forma, caso haja descumprimento das metas acordadas, tanto as montadoras, quanto as importadoras, terão que arcar com uma multa de até $20 \%$ sobre as vendas realizadas (BRASIL, 2018).

Destaca-se que, dentre as políticas nacionais (consideradas como as principais inciativas), existem ainda uma séria de outras políticas, regionais e locais, promovidas por governos estaduais e municipais, que também visam promover o mercado de EVs. Na cidade de São Paulo (SP), por exemplo, os carros elétricos passaram a não fazer parte do rodízio municipal de veículos. Na cidade de Campinas (SP), planeja-se criar uma "Área Branca", livre da circulação de veículos à combustão interna, na região central da cidade (FGV, 2018).

No entanto, independentemente, de se tratarem de iniciativas nacionais ou não, quando são tomadas experiências internacionais como base para o desenvolvimento de políticas próprias, deve-se observar não apenas o incentivo à produção e comercialização do produto alvo, mas sim toda a infraestrutura necessária para suportar tal mercado (HARRISON et al., 2017). De acordo com Jatoba (2014), apesar de a estrutura mecânica de um veículo 100\% elétrico ser bastante simplificada, o veículo exige investimentos em infraestrutura, como sistema de geração, postos de reabastecimento e uma rede de recarga preparada. Por serem, em sua maioria, abastecidos através da rede elétrica, os EVs ainda necessitam de um tempo de 
recarga longo, entre 6 e 12 horas, o que requer um sistema de distribuição de energia com cabeamento bem mais robusto que o convencional. Segundo Vidhi et al. (2018), a falta de apoio às políticas de infraestruturas pelo governo acaba refletindo em uma implantação lenta dos EVs.

Rosato et al. (2017) destacam que a adoção generalizada de EVs resultaria em uma eletricidade doméstica com características de demanda radicalmente diferentes, representando uma ameaça à estabilidade da rede elétrica. Nesta perspectiva, a microcogeração e geração distribuída são consideradas, pela comunidade europeia, como algumas das medidas mais eficazes para economizar energia primária, reduzir as emissões e reduzir o impacto dos EVs na rede elétrica. Somado a isto, Moriarty et al. (2017) e Van Mierlo et al. (2017) ressaltam ainda que os EVs podem ser potencialmente poluidores quando alimentados por energia elétrica proveniente de fontes não renováveis, como gás natural, carvão, petróleo e derivados. No caso do Brasil, tanto as iniciativas de micro e cogeração, quanto as de geração distribuída, são ainda muito incipientes.

Considerando este cenário, surgiram as seguintes questões de investigação: (i) qual seria a média de consumo de energia de um EV para o perfil de rodagem do brasileiro? (ii) qual seria o impacto no consumo de energia elétrica de uma frota projetada de EVs? O Brasil possui potencial de geração suficiente para suportar tal demanda? Nesse contexto, este estudo tem como principal objetivo responder a estes questionamentos através da análise de dados técnicos e estatísticos divulgados pelo governo e entes do segmento automotivo.

\section{METODOLOGIA}

Considerando os dados de consumo elétrico de um modelo de EV e da quilometragem média percorrida pelo brasileiro, foi estimado o consumo elétrico de uma determinada frota de EVs. Em seguida, foi realizada uma comparação entre o potencial de geração do Brasil frente a este novo potencial de consumo, além de uma análise de viabilidade do modelo de negócio da eletrificação veicular. O fluxograma na Figura 2 apresenta as etapas seguidas na aplicação da metodologia utilizada no estudo.

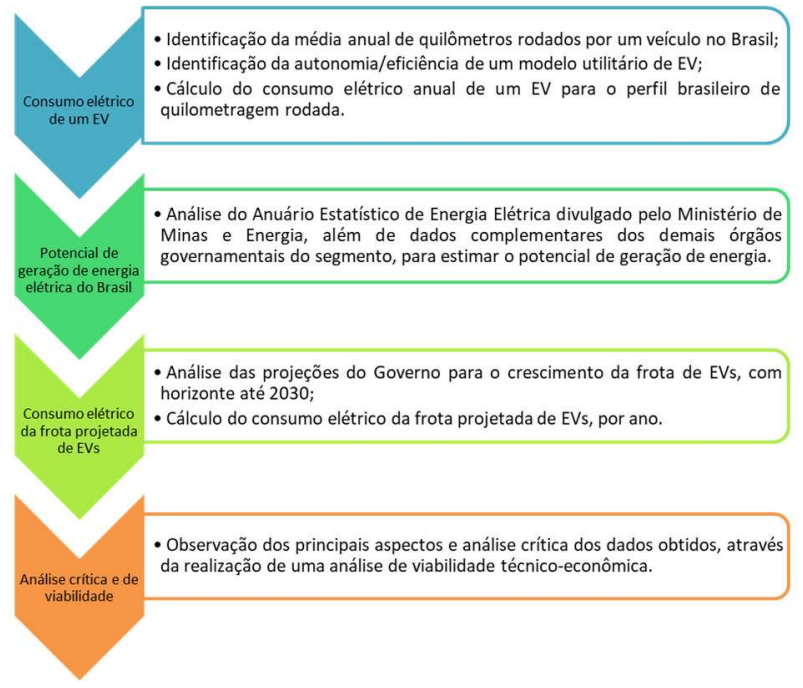

Figura 2: Fluxograma mostrando as etapas seguidas na revisão científica abordando a infraestrutura energética brasileira, considerando as perspectivas e desafios para o suporte aos veículos elétricos. 


\section{Estimativa do consumo elétrico de um EV no Brasil}

Considerando os dados da média de circulação $(\mathrm{km})$ de um veículo, por Estado, no Brasil, foi calculado o perfil de rodagem do brasileiro através da média entre os resultados obtidos nos Estados.

Objetivando a simplificação dos cálculos e redução do erro (devido ao grau de incerteza quanto ao volume de veículos de grande porte que migrarão para a eletrificação), neste estudo, considerou-se toda a frota futura de veículos elétricos como sendo composta unicamente por veículos de passeio. Assim, para identificação do consumo médio de um EV, foram observados os dados de eficiência presentes na ficha técnica de um veículo de passeio de uma das principais montadoras de EVs do mundo.

Visando a identificação do consumo elétrico anual de um EV, nas condições de uso brasileiras, foram cruzados os dados de eficiência do veículo com a quilometragem média percorrida por um carro utilitário no Brasil.

\section{Potencial de geração de energia elétrica do Brasil}

Analisando o Anuário Estatístico de Energia Elétrica, divulgado pela Empresa de Pesquisa Energética (EPE) e de dados da Agência Nacional de Energia Elétrica (ANEEL), órgãos pertencentes ao Ministério de Minas e Energia (MME), foram relacionadas as várias fontes de geração de energia do Brasil, classificando-as entre fontes renováveis e não renováveis. Adicionalmente, foi identificado o potencial instalado e efetivo de geração de energia elétrica, com destaque para a parcela de energia importada para complementar a demanda interna de consumo.

\section{Consumo elétrico da frota projetada de EVs}

Baseado na perspectiva de crescimento do mercado de veículos elétricos no Brasil até 2030, promovida pelas políticas de incentivos governamentais, e no cálculo realizado para estimar o consumo de um modelo utilitário de EV, foi novamente calculada a estimativa de consumo, entretanto, para uma frota e não apenas para um único veículo.

Os resultados foram apresentados, anualmente, de 2019 a 2030, de forma acumulada e o acréscimo de consumo relativo aos EVs foi comparado com a capacidade de geração efetiva atual do Brasil.

\section{Análise crítica e de viabilidade}

Considerando o nível de emissão da frota veicular brasileira, anterior às políticas de eficiência energética do Inovar Auto e Rota 2030, e considerando o perfil de quilometragem média percorrida por um carro no Brasil, foi calculado o nível de emissões de $\mathrm{CO}_{2}$ evitado pela frota de veículos elétricos projetada até 2030. Com base na quantidade de toneladas de carbono não emitidas e no valor de cotação do crédito de carbono, foi calculada a remuneração do projeto de eletrificação veicular brasileiro. Para fins comparativos e de análise de viabilidade, a mesma remuneração foi calculada para uma frota de veículos flex (baseada na quantidade de veículos flex licenciados em 2019), considerando a possibilidade destes veículos serem 
abastecidos com álcool, já que o álcool também pode ser considerado uma fonte de emissão zero, pois considera-se o efeito de compensação, através do replantio da cana-de-açúcar (RIBEIRO et al., 2010).

Mediante os resultados obtidos, foi realizada uma análise crítica sobre a infraestrutura necessária para suportar o crescimento do mercado de EVs no Brasil, bem como, sobre a viabilidade técnico-econômica dos veículos elétricos frente a outras tecnologias, como solução para mitigação da emissão de GEE.

\section{RESULTADOS E DISCUSSÃO}

De modo geral, os dados obtidos na literatura consultada permitiram traçar um perfil atualizado do consumo elétrico veicular e do tamanho projetado para a frota de veículos, a partir do qual foi possível elaborar um diagnóstico, considerando o avanço da inserção de veículos elétricos no cenário brasileiro.

\section{Consumo elétrico de um EV}

Segundo pesquisa realizada pela Kelley Blue Book, a partir da análise de dados e big data de mais de um milhão de veículos em todo o Brasil, foi apontada a média de circulação anual dos motoristas, por Estado (KBB BRASIL, 2019), conforme Tabela 2.

Tabela 2: Média de circulação $(\mathrm{km})$ de um veículo, por Estado, no Brasil, em 2019.

\begin{tabular}{llllll}
\hline Estado & Média de circulação $(\mathbf{k m})$ & Estado & Média de circulação $\mathbf{( k m})$ & Estado & Média de circulação $(\mathbf{k m})$ \\
\hline TO & 17.600 & PR & 13.100 & AP & 12.500 \\
DF & 14.600 & SE & 13.100 & BA & 12.500 \\
MT & 14.600 & MA & 13.000 & RO & 12.500 \\
RR & 14.300 & SP & 13.000 & RS & 12.200 \\
GO & 13.700 & AL & 12.900 & PA & 12.100 \\
MS & 13.700 & MG & 12.900 & CE & 11.900 \\
RN & 13.400 & AM & 12.800 & ES & 11.700 \\
AC & 13.300 & SC & 12.800 & RJ & 11.600 \\
PB & 13.100 & PI & 12.600 & PE & 11.100 \\
\hline
\end{tabular}

Fonte: Adaptado de KBB BRASIL (2019).

A média de circulação por um veículo no Brasil foi obtida pela média dos valores de cada Estado, resultando em um valor médio de $13 \mathrm{mil} \mathrm{km/ano.}$

Para a identificação do consumo elétrico de um EV, foi escolhido o modelo Bolt EV, da Chevrolet, por ser um modelo de veículo utilitário e o primeiro carro elétrico da marca no país. Além disso, comparativamente, trata-se do EV de maior autonomia em sua faixa de preço, transpondo inclusive elétricos de categoria superior, sendo um dos modelos de melhor aceitação popular no mundo (VIEIRA, 2019).

Segundo a ficha técnica do veículo, divulgada pelo fabricante (CHEVROLET, 2020), o Chevrolet Bolt EV possui um pack de baterias com capacidade de $66 \mathrm{kWh}$ e uma autonomia de, aproximadamente, $416 \mathrm{~km}$.

Portanto, foram nomeados o $\mathrm{CE}_{\mathrm{AM}}$ como sendo o consumo elétrico para autonomia máxima do veículo, em kWh ( $\left.C E_{A M}=66\right) ; A M$ a autonomia máxima do veículo, em $\mathrm{km}(\mathrm{AM}=416) ; \mathrm{K} \mathrm{ABA}_{\mathrm{BR}}$ a quilometragem anual média percorrida por um brasileiro, em km (KA $\left.A_{B R A}=13.000\right)$; e $C E A_{B R A} O$ consumo elétrico anual de um veículo, segundo perfil brasileiro, em kWh (CEA $A_{B R A}=$ ?).

Com base nestes dados, foi possível estimar, por meio de regra de três simples, o consumo elétrico de um EV para a realidade de tráfego brasileira (Equação 1). 


$$
\begin{gathered}
\mathrm{CEA}_{\mathrm{BRA}} \times \mathrm{AM}=\mathrm{CE}_{\mathrm{AM}} \times \mathrm{KA} \mathrm{A}_{\mathrm{BRA}}(\text { Equação } 1) \\
\mathrm{CEA}_{\mathrm{BRA}} \times 416=66 \times 13.000 \\
\mathrm{CEA}_{\mathrm{BRA}}=2.062,5 \mathrm{kWh} \rightarrow \mathrm{CEA}_{\mathrm{BRA}}=2,1 \mathrm{MWh}
\end{gathered}
$$

A partir das premissas assumidas anteriormente, foi possível estimar que o consumo elétrico médio anual correspondente a um modelo utilitário de EV é de 2,1 MWh.

\section{Potencial de geração de energia elétrica do Brasil}

A matriz elétrica é o conjunto de fontes de geração de um país, responsáveis por suprir a necessidade (demanda) de eletricidade. O somatório da capacidade de geração destas várias fontes corresponde ao potencial de geração de energia elétrica.

No Brasil, a matriz atual é majoritariamente renovável, isso porque grande parte da energia elétrica gerada vem de usinas hidrelétricas (65,2\%). As demais fontes são gás natural $(10,5 \%)$, biomassa $(8,2 \%)$, solar e eólica (6,9\%), carvão (4,1\%), nuclear (2,5\%) e petróleo e derivados (2,6\%) (EPE, 2018).

Segundo levantamento da Agência Nacional de Energia Elétrica, apesar de possuir mais de 178 GW de capacidade instalada (o que corresponderia a uma geração de 1.537 TWh de energia), o Brasil não é autossuficiente em produção de energia, importando ainda 4,6\% de sua demanda de outros países como o Paraguai, Argentina, Venezuela e Uruguai (ANEEL, 2019). Destaca-se ainda que, nem toda a capacidade instalada é convertida em energia, dada a intermitência de algumas das fontes renováveis que estão sujeitas a variações climáticas, e ao grau de eficiência de cada tecnologia. De acordo com o anuário estatístico de energia elétrica de 2019, divulgado pela EPE, de toda a potência instalada, efetivamente, apenas $601 \mathrm{TWh}$ foram convertidos em energia elétrica (EPE, 2019).

Ao comparar a matriz elétrica do Brasil com a da China, país em que os veículos elétricos foram largamente adotados, temos o Brasil com uma matriz majoritariamente renovável (83\%) (EPE, 2018), enquanto que a China com uma matriz majoritariamente fóssil (86\%) (GÓMEZ et al., 2012). A partir da avaliação de Li (2016), observou-se que a implantação de EVs na China, essencialmente, transfere o uso de gasolina para a geração de energia a carvão (energia de base da China), levando a um maior consumo de carvão e, consequentemente, a um aumento das emissões de $\mathrm{CO}_{2}$. Nesse sentido, Li (2016) concluí que a estratégia chinesa não é a de reduzir as emissões de GEE, mas sim de transferir a poluição dos grandes centros urbanos para locais mais afastados, onde estão situadas as usinas de geração de energia.

Desta forma, fica evidenciado que, apesar de o Brasil ter uma matriz em sua maior parte limpa, é necessário que qualquer incremento de consumo devido aos EVs seja amparado por uma ampliação da capacidade de geração de energia renovável, caso contrário poderá haver apenas a transferência geográfica da poluição, como no caso da China.

\section{Consumo elétrico da frota projetada de EVs}

Segundo dados da ANFAVEA (2019), nos últimos cinco anos (2015-2019), contabilizando os veículos importados, foram licenciados 21.061 EVs no Brasil, dos quais, 11.858 apenas em 2019. Muito deste aumento 
se deve às políticas de incentivos governamentais.

Baseado na maior agressividade do fomento a este segmento de transporte, como já relatado anteriormente, estima-se que, até 2030, o Brasil conte com 5\% de sua frota de carros composta por EVs. Essa frota corresponderá a, aproximadamente, 2 milhões de EVs, havendo uma meta anual de 180 mil novos veículos licenciados/ano (BCG, 2019).

Diante dessa estatística, e tomando por base o modelo de projeção de consumo elétrico apresentado na Figura 3, com o consumo anual de 2,1 MWh como sendo o consumo elétrico correspondente a um modelo utilitário de EV, foi possível calcular o incremento de demanda energética relativa à frota projetada de veículos elétricos, até 2030 (Tabela 3).

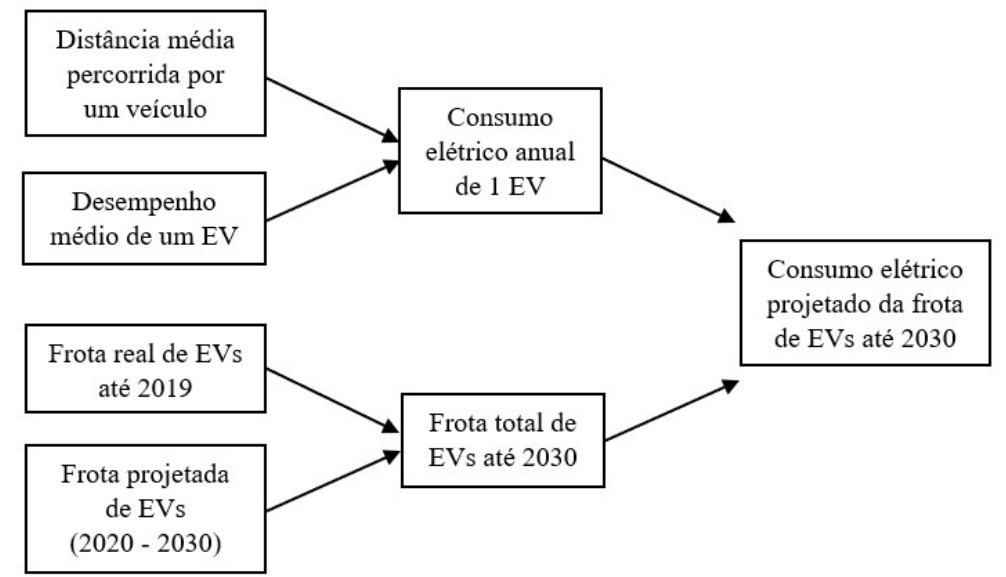

Figura 3: Fluxograma do modelo de projeção de consumo da frota de veículos elétricos de 2019 até 2030 , no Brasil.

Tabela 3: Consumo projetado da frota de veículos elétricos, de 2019 até 2030, no Brasil.

\begin{tabular}{lll}
\hline Ano & Frota acumulada (unidades) & Consumo incremental (Mwh) \\
\hline Até 2019 & 21.061 & 44.228 \\
2020 & 201.061 & 422.228 \\
2021 & 381.061 & 800.228 \\
2022 & 561.061 & 1.178 .228 \\
2023 & 741.061 & 1.556 .228 \\
2024 & 921.061 & 1.934 .228 \\
2025 & 1.101 .061 & 2.312 .228 \\
2026 & 1.281 .061 & 2.690 .228 \\
2027 & 1.461 .061 & 3.068 .228 \\
2028 & 1.641 .061 & 3.446 .228 \\
2029 & 1.821 .061 & 3.824 .228 \\
2030 & 2.001 .061 & 4.202 .228 \\
\hline
\end{tabular}

*Números em negrito indicam o consumo incremental de energia projetado para a frota de EVs estimada.

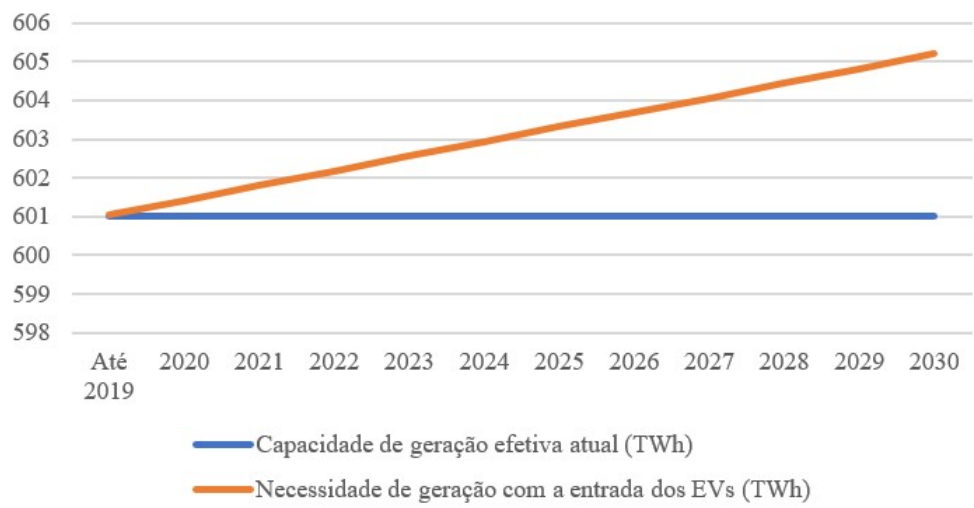

Figura 4: Capacidade de geração atual versus crescimento da demanda devido aos veículos elétricos. 
Assim sendo, foi possível estimar em 4,2 TWh o acréscimo do consumo de energia necessário para suportar a introdução dos EVs, no mercado brasileiro de transportes. Tomando por base o registro mais recente da capacidade efetiva de geração do Brasil, divulgado pela EPE, é possível analisar o comportamento deste acréscimo de energia ao longo do tempo (Figura 4).

\section{Análise crítica e de viabilidade}

Considerando que o consumo adicional de energia referente a entrada dos veículos elétricos será de 4,2 TWh, para atendimento dessa demanda, a título de comparação com as estruturas geradoras de energia já existentes no país, seria necessário a construção de: (i) uma geradora do porte da Usina Nuclear Angra I, que, segundo a Eletrobrás (2020), em 2019 alcançou sua melhor marca de geração com 5,5 TWh; (ii) ou a construção de três centrais hidrelétricas do porte de Sobradinho, que em 2018 chegou a produzir 1,5 TWh (CHESF, 2019). Segundo o site Globo em 2018, para construção de uma Usina com o porte de Angra I, seria necessário um investimento na ordem de 6 bilhões de reais. Ademais, é importante destacar que, para suportar a entrada dos EVs no mercado brasileiro, o investimento necessário em infraestrutura não se restringe apenas a construção de novas geradoras de energia, também existe a necessidade de investimento massivo em redes de distribuição de energia e eletropostos para recarga destes veículos.

Sabendo-se que o crédito de carbono é tido como uma "commodity ambiental" cujo valor oscila influenciado por fatores de mercado, para evidenciar a real vantagem competitiva da solução da eletrificação veicular, foi assumido o valor do crédito de carbono de 18,99 euros/ton, conforme dados de fechamento da bolsa de valores (INVESTING, 2020). Levando-se em consideração ainda a cotação do euro no dia (01/05/2020 - 6,01 reais), a frota de veículos elétricos projetada até 2030, as emissões de 166 gCO $/ \mathrm{km}_{\text {no }}$ Brasil (antes das políticas de eficiência energética), e a média de $13.000 \mathrm{~km}$ percorridos anualmente por um veículo no Brasil, foi obtido o ganho demonstrado na Tabela 4.

Tabela 4: Ganhos ambiental e financeiro devido aos veículos elétricos, de 2019 até 2030, no Brasil.

\begin{tabular}{llll}
\hline Ano & Frota acumulada (unidades) & Créditos de carbono (ton $\mathbf{C O}_{\mathbf{2}}$ ) & Ganho financeiro (R\$ - bilhão) \\
\hline Até $\mathbf{2 0 1 9}$ & 21.061 & $45.449,64$ & $5.187,16$ \\
$\mathbf{2 0 2 0}$ & 201.061 & $433.889,64$ & $49.519,78$ \\
$\mathbf{2 0 2 1}$ & 381.061 & $822.329,64$ & $93.852,40$ \\
$\mathbf{2 0 2 2}$ & 561.061 & $1.210 .769,64$ & $138.185,02$ \\
$\mathbf{2 0 2 3}$ & 741.061 & $1.599 .209,64$ & $182.517,64$ \\
$\mathbf{2 0 2 4}$ & 921.061 & $1.987 .649,64$ & $226.850,25$ \\
$\mathbf{2 0 2 5}$ & 1.101 .061 & $2.376 .089,64$ & $271.182,87$ \\
$\mathbf{2 0 2 6}$ & 1.281 .061 & $2.764 .529,64$ & $315.515,49$ \\
$\mathbf{2 0 2 7}$ & 1.461 .061 & $3.152 .969,64$ & $359.848,11$ \\
$\mathbf{2 0 2 8}$ & 1.641 .061 & $3.541 .409,64$ & $404.180,73$ \\
$\mathbf{2 0 2 9}$ & 1.821 .061 & $3.929 .849,64$ & $448.513,35$ \\
$\mathbf{2 0 3 0}$ & 2.001 .061 & $4.318 .289,64$ & $492.845,96$ \\
\hline Total & & $\mathbf{2 6 . 1 8 2 . 4 3 5 , 6 6}$ & $\mathbf{2 . 9 8 8 . 1 9 8 , 7 6}$
\end{tabular}

Desta forma, é demostrada uma expectativa de redução de mais de 26,1 milhões de toneladas de $\mathrm{CO}_{2}$, devido a entrada dos veículos elétricos, até 2030, o que corresponderia a um ganho financeiro de mais de 2,9 quadrilhões de reais, em créditos de carbono.

Como comparação, calcularam-se os ganhos ambiental e financeiro da frota de veículos flex 
licenciados em 2019 (2.328.650 carros), segundo dados da ANFAVEA (2019). Para tal, foi considerado o abastecimento destes veículos unicamente com álcool, uma vez que o álcool também pode ser considerado uma fonte de emissão zero, dada a possibilidade de compensação através do replantio da cana-de-açúcar. Para projetar a frota acumulada até 2030, considerou-se a mesma quantidade de veículos licenciados em 2019 entrando a cada novo ano. Por conservadorismo, não foi adotada nenhuma taxa de crescimento anual. Assim, tomando por base estas e as demais considerações assumidas para o cálculo dos ganhos dos EVs, o resultado obtido para a frota de veículos flex é apresentada na Tabela 5.

Tabela 5: Ganhos ambiental e financeiro devido aos veículos flex, de 2019 até 2030, no Brasil.

\begin{tabular}{|c|c|c|c|}
\hline Ano & Frota acumulada (unidades) & Créditos de carbono (ton $\mathrm{CO}_{2}$ ) & Ganho financeiro \\
\hline Até 2019 & 2.328 .650 & $5.025 .226,70$ & $573.528,62$ \\
\hline 2020 & 4.657 .300 & $10.050 .453,40$ & $1.147 .057,24$ \\
\hline 2021 & 9.314 .600 & $20.100 .906,80$ & $2.294 .114,48$ \\
\hline 2022 & 18.629 .200 & $40.201 .813,60$ & $4.588 .228,97$ \\
\hline 2023 & 37.258 .400 & $80.403 .627,20$ & $9.176 .457,93$ \\
\hline 2024 & 74.516 .800 & $160.807 .254,40$ & $18.352 .915,86$ \\
\hline 2025 & 149.033 .600 & $321.614 .508,80$ & $36.705 .831,73$ \\
\hline 2026 & 298.067 .200 & $643.229 .017,60$ & $73.411 .663,46$ \\
\hline 2027 & 596.134 .400 & $1.286 .458 .035,20$ & $146.823 .326,91$ \\
\hline 2028 & 1.192 .268 .800 & $2.572 .916 .070,40$ & $293.646 .653,82$ \\
\hline 2029 & 2.384 .537 .600 & $5.145 .832 .140,80$ & $587.293 .307,65$ \\
\hline 2030 & 4.769.075.200 & $10.291 .664 .281,60$ & $1.174 .586 .615,29$ \\
\hline Total & & $20.578 .303 .336,50$ & 2.348.599.701,96 \\
\hline
\end{tabular}

Mediante análise dos resultados, é possível afirmar que, apesar de os EVs demonstrarem ganhos tanto ambientais, quanto financeiros, a hipótese de abastecer os veículos flex com álcool apresenta resultados bem superiores, com uma redução de mais de 20,5 bilhões de toneladas de $\mathrm{CO}_{2}$ emitidos e a mais de 2,3 quintilhões de reais, em créditos de carbono.

Sabendo-se que: (i) o agronegócio sempre foi um forte pilar da economia brasileira, correspondendo em 2019 a 21\% do Produto Interno Bruto (PIB), segundo dados da Confederação da Agricultura e Pecuária do Brasil (CNA, 2020); (ii) os carros movidos a biocombustíveis são, na realidade, uma modalidade de veículos à combustão e que, portanto, para serem implementados em larga escala não necessitariam de grandes investimentos em infraestrutura, a não ser a de produção dos próprios biocombustíveis, é necessário se reavaliar, de forma pragmática, a futura entrada de EVs no mercado automobilístico brasileiro.

Tendo em vista os indicadores ambiental e financeiro aqui apresentados, observa-se que o modelo de mobilidade a partir de biocombustíveis figura como, possivelmente, mais viável que a eletrificação, no Brasil, nas atuais circunstâncias e considerando as simplificações adotadas neste estudo, uma vez que, como relatado por Soares et al. (2009), mesmo sendo derivados de materiais vegetais compostos por carbono oriundo exclusivamente do $\mathrm{CO}_{2}$ atmosférico, as etapas de produção de qualquer biocombustível ainda requerem a utilização de fontes fósseis de carbono, e por decorrência disso, também são fontes indiretas de poluição.

\section{CONCLUSÕES}

Apesar de, em operação, os EVs gerarem reduzidas quantidades de GEE, o mesmo não se pode 
afirmar quanto às suas emissões indiretas. Como já ressaltado anteriormente, se alimentados por fontes de energia fósseis, os EVs podem ser considerados como verdadeiras fontes poluidoras. No Brasil, essas fontes correspondem a $17 \%$ da matriz energética, segundo dados da EPE. Nesse sentido, se o objetivo da migração do modelo tradicional de transportes para elétrico é melhorar o desempenho ambiental, através da mitigação dos GEE, é necessário que a política de incentivo deste mercado automotivo esteja atrelada a uma política de expansão das fontes de geração de energia renovável.

Outro aspecto relevante a ser observado é a falta de conexão entre as políticas de promoção da tecnologia de eletrificação e as políticas de expansão da infraestrutura elétrica para atender os EVs, observando aspectos além da geração de energia, como a confiabilidade do sistema de distribuição de eletricidade. Uma vez que a carga elétrica aumenta, é necessário que todo o cabeamento e a infraestrutura de suporte estejam dimensionados para atender a demanda. A estratégia adotada pelo governo através do Inovar Auto e do Rota 2030 visa apenas o fomento para que as montadoras automotivas fabriquem carros mais eficientes, sem prever, porém, investimentos em infraestrutura que suportem tais iniciativas, o que pode acabar refletindo em uma implantação lenta dos EVs.

Destaca-se também que, dada a inexistência de regulamentação quanto aos encargos de mobilidade elétrica estabelecida pela ANEEL, que servirão de remuneração para as comercializadoras de energia, o valor cobrado pela recarga dos veículos em eletropostos, torna o negócio não atrativo. Portanto, as comercializadoras de energia que irão investir em estações de carregamento público, deverão avaliar o impacto dos EVs na rede de distribuição local e também aprender como desenvolver e operar sua própria rede de recarga.

Finalmente, destaca-se ainda como alternativa a introdução dos EVs, o fomento aos veículos movidos a biocombustíveis. Apesar da análise ter sido realizada introduzindo o álcool como combustível, ainda existe uma gama de outros biocombustíveis, até energeticamente mais eficientes, e que poderiam ser viabilizados mais rapidamente através de incentivos governamentais. Destaca-se, contudo que, da mesma forma que os EVs, os veículos movidos a biocombustíveis também não estão livres de emissões de GEE. Mesmo sendo derivados de materiais vegetais, as etapas de produção de qualquer biocombustível ainda requerem a utilização de fontes fósseis de carbono.

\section{REFERÊNCIAS}

ANEEL. Agência Nacional de Energia Elétrica. Matriz de Capacidade de Geração e Operação do Brasil. Brasília: MME, 2019

ANFAVEA. Associação Nacional dos Fabricantes de Veículos Automotores. Estatísticas de Veículos. São Paulo: ANFAVEA, 2019.

BCG. Boston Consulting Group. Carro Elétrico no Brasil. São Paulo: BCG, 2019.

BNEF. Bloomberg New Energy Finance. Electric Vehicle Outlook 2018. New York: BNEF, 2018.
BRASIL. Lei 12.715: Programa de Incentivo à Inovação Tecnológica e Adensamento da Cadeia Produtiva de Veículos Automotores. Brasília: Presidência da República, 2012.

BRASIL. Lei 13.755: Programa Rota 2030: Mobilidade e Logística. Brasília: Presidência da República, 2018.

CHESF. Companhia Hidroelétrica do São Francisco. Relatório da Administração 2018. Recife: CHESF, 2019.

CHEVROLET. Ficha Técnica do Bolt EV. Mogi das Cruzes: GM, 2020.

CNA. Confederação da Agricultura e Pecuária do Brasil. 
Panorama do Agro. Brasília: CNA, 2020.

ELETROBRAS. Eletrobras Eletronuclear. Angra 1. Rio de Janeiro: ELETROBRAS, 2020

EPE. Empresa de Pesquisa Energética. Anuário Estatístico de Energia Elétrica 2019. Rio de Janeiro: MME, 2019.

EPE. Empresa de Pesquisa Energética. Matriz Energética e Elétrica. Rio de Janeiro: MME, 2018.

FGV. Fundação Getulio Vargas. O mercado de veículos elétricos no Brasil: os avanços e as lições aprendidas. Rio de Janeiro: FVG Energia, 2018.

GÓMEZ, J. M.; CHAMON, P. H.; LIMA, S. B.. Towards a new world energy order? potentialities and perspectives of the energy issue between the BRICS countries. Contexto Internacional, Rio de Janeiro, v.34, n.2, 2012. DOI: http://dx.doi.org/10.1590/S0102-85292012000200006

HARRISON, G.; THIEL, C.. An exploratory policy analysis of electric vehicle sales competition and sensitivity to infrastructure in Europe. Technological Forecasting and Social Change, v.114, p.165-178, 2017. DOI: https://doi.org/10.1016/j.techfore.2016.08.007

INVESTING. Commodities: Crédito Carbono Futuros (CFI2ZO). Tortola: Fusion Media Limited, 2020.

JATOBÁ, R.. A diferença entre carros híbridos e elétricos. São Paulo: Universo Jatobá, 2014

KBB BRASIL. Você sabe quanto a quilometragem impacta o preço do carro usado?. São Paulo: Kelley Blue Book, 2019.

LI, Y.. Infrastructure to Facilitate Usage of Electric Vehicles and its Impact. Transportation Research Procedia, v.14, p.2537-2543, 2016. DOI: https://doi.org/10.1016/j.trpro.2016.05.337

MORIARTY, P.; WANG, S. J.. Can Electric Vehicles Deliver Energy and Carbon Reductions? Energy Procedia, v.105, p.2983-2988, 2017. DOI: https://doi.org/10.1016/j.egypro.2017.03.713

MOURA, M.. Tendências do Mercado Automotivo. Recife: Acumuladores Moura, 2019.

PERUJO, A.; THIEL, C.; NEMRY, F.. Electric vehicles in urban context: environmental benefits and techno-economic barriers. In: SOYL, S.. Electric vehicles: the benefits and barriers. 2011.

RIBEIRO, J. M.; MACÁRIO, R.; REIS, V.. Soluções mitigadoras das emissões poluentes nos aeroportos. In: PLURIS 2010 CONGRESSO LUSO-BRASILEIRO PARA O PLANEAMENTO URBANO, REGIONAL, INTEGRADO, SUSTENTÁVEL, 4. Anais. Faro: Universidade do Algarve, 2010.

ROSATO, A.; SIBILIO, S.; CIAMPI, G.; ENTCHEV, E.; RIBBERINK, $\mathrm{H}$.. Energy, Environmental and Economic Effects of Electric Vehicle Charging on the Performance of a Residential Building-integrated Micro-trigeneration System. Energy Procedia, v.111, n.September 2016, p.699-709, 2017. DOI: https://doi.org/10.1016/i.egypro.2017.03.232

SOARES, L. H. B.; ALVES, B. J. R.; URQUIAGA, S.; BODDEY, R. M.. Mitigação das emissões de gases de efeito estufa pelo uso de etanol da cana-de-açúcar produzido no Brasil. Seropédica: Embrapa, 2009.

VAN MIERLO, J.; MESSAGIE, M.; RANGARAJU, S.. Comparative environmental assessment of alternative fueled vehicles using a life cycle assessment. Transportation Research Procedia, v.25, p.3439-3449, 2017. DOI: https://doi.org/10.1016/j.trpro.2017.05.244

VIDHI, R.; SHRIVASTAVA, P.. A review of electric vehicle lifecycle emissions and policy recommendations to increase EV penetration in India. Energies, v.11, n.3, p.1-15, 2018. DOI: $\underline{\text { https://doi.org/10.3390/en11030483 }}$

VIEIRA, A.. O Chevrolet Bolt começa a ser vendido em vendido em outubro. Sorocaba: Jornal Cruzeiro, 2019.

WRI BRASIL. Dados de emissões de $\mathrm{CO}_{2}$ do Brasil. São Paulo: World Resources Institute, 2018.

A CBPC - Companhia Brasileira de Produção Científica (CNPJ: 11.221.422/0001-03) detém os direitos materiais desta publicação. Os direitos referem-se à publicação do trabalho em qualquer parte do mundo, incluindo os direitos às renovações, expansões e disseminações da contribuição, bem como outros direitos subsidiários. Todos os trabalhos publicados eletronicamente poderão posteriormente ser publicados em coletâneas impressas sob coordenação da Sustenere Publishing, da Companhia Brasileira de Produção Científica e seus parceiros autorizados. Os (as) autores (as) preservam os direitos autorais, mas não têm permissão para a publicação da contribuição em outro meio, impresso ou digital, em português ou em tradução. 